\title{
Correction to: first year students' experience in a CyberWorld course - an evaluation
}

\section{Frank Breitinger ${ }^{1,2} \cdot$ Ryan Tully-Doyle ${ }^{1} \cdot$ Kristen Przyborski $^{1} \cdot$ Lauren Beck $^{1}$ • Ronald S. Harichandran ${ }^{1}$}

Published online: 11 September 2020

(C) Springer Science+Business Media, LLC, part of Springer Nature 2020

\section{Correction to: Educational and Information Technologies https://doi.org/10.1007/s10639-020-10274-5}

The published version of this article unfortunately contains blinded information.

In the 3rd paragraph, 1st line of the Introduction, the "blinded review" in the sentence "At the blinded for review, University of New Haven..." must be removed.

In the 5th line of the same paragraph, "[ref blinded for review]" is changed to [Przyborski et al. 2019].

The original article has been corrected.

Publisher's note Springer Nature remains neutral with regard to jurisdictional claims in published maps and institutional affiliations.

The online version of the original article can be found at https://doi.org/10.1007/s10639-020-10274-5

\section{Frank Breitinger}

frank.breitinger@uni.li; FBreitinger@newhaven.edu

Ryan Tully-Doyle

RTullyDoyle@newhaven.edu

Kristen Przyborski

KPrzyborski@newhaven.edu

Lauren Beck

LBeck@newhaven.edu

Ronald S. Harichandran

RHarichandran@newhaven.edu

1 University of New Haven, 300 Boston Post Rd, West Haven, CT 06516, USA

2 Hilti Chair for Data and Application Security, University of Liechtenstein, Vaduz, Liechtenstein 